\title{
Improving distance education through Programme Quality Assurance
}

\author{
Bill Davey and Arthur Tatnall \\ School of Information Technology, RMIT University, Melbourne, Australia \\ School of Information Systems, Victoria University, Melbourne, Australia
}

\begin{abstract}
This paper describes the experiences of a major Australian university in the implementation of a system of Programme Quality Assurance (PQA), to shed light on improving the quality of global distance education programs. The system described makes use of quality cycles to enhance the quality of all university programmes. The study, which involved a series of interviews with several of the stakeholders in this system, found that some mistakes had been made in initial systems implementation that resulted in a number of academic staff distrusting the system. It illustrated, however, that use of this system was acknowledged by most stakeholders as an important contributor to improving quality in distance education, rather than just measuring it.
\end{abstract}

Key words: Distance education, programme quality assurance.

\section{INTRODUCTION}

A system of Programme Quality Assurance (PQA) was introduced at the University in 1993 to ensure continuous improvement in all programmes, including a wide range of distance education programmes. It could not, however, be said that its introduction was without controversy among the university's academic staff. With hindsight, implementation mistakes were made and some aspects of the system did not work as well as they should have. In this paper we will argue that the system has major advantages and serves well the goal of continuous improvement in educational quality.

When this system was proposed in 1993 the term used was Educational Quality Assurance (EQA), but in subsequent revisions this was changed to PQA. John Bowden, the then Director of Education Programme

The original version of this chapter was revised: The copyright line was incorrect. This has been corrected. The Erratum to this chapter is available at DOI: 10.1007/978-0-387-35700-3_33 
Improvement, says that this system was set up to demonstrate educational accountability and also in a genuine attempt to make teaching and learning in the university better. He insists the system is well based in educational theory and that 'the approach that the University has taken to educational quality assurance has been to attempt to achieve an appropriate balance between improvement and accountability aspects of quality assurance...' (Bowden 1997 :2).

\section{DISTANCE EDUCATION AT THE UNIVERSITY}

Although the University delivers most of its classes in its Australian classrooms it also has a commitment to numerous programmes that involve distance education across various parts of Asia. It is a member of the Global University Alliance (GUA) and Open Learning Australia (OLA) and in both these programmes it delivers units that are taken completely online. Units are also delivered by other university partners so that a student can make up a whole programme from amongst these offerings. The University also delivers some degrees completely online and while enrolments are comparatively small at present some programmes have been offered for several years.

In common with many other Australian universities (Marginson 2002), in addition to its local offerings, the University also offers most of its programmes in countries other than Australia. In most cases this involves an off-shore partner providing facilities and the programme being delivered by visiting lecturers, supported by technology, and a local tutor. Students study with two weeks or less of Australian presence and are supported electronically for the remaining time. This is not distance education for students as they study in a traditional building, but it is study at a distance for the University.

The University has infrastructure support for distance education that arises from its normal operations. Information Technology Services provide networking services that include intranet and WAN facilities to educators. The Learning Technology Services unit provides the Distributed Learning System (DLS) which offers Web-based delivery products such as Blackboard and Web-CT in an integrated environment. The DLS is used by almost every course within the University to deliver materials to students and sometimes to provide interactive communication outside the classroom. 


\section{HOW THE UNIVERSITY ADOPTED ITS SYSTEM OF PROGRAMME QUALITY ASSURANCE}

In the early 1990s, in response to Commonwealth Government initiatives relating to the quality of university education, the University had a need to design a suitable system to ensure the quality of all its educational programmes. We will not delve too far here into what might be meant by educational quality (Vidovich, Fourie et al. 2000; Gilroy, Long et al. 2001), except to say that it was seen to relate to ensuring that course documentation reflected practice and assisted in the improvement of practice. In late 1993 Bowden was given the task of going around the University to speak about the need to introduce some sort of EQA system, and to discuss how this might be done.

In an explanatory document, Bowden and Boyle (1995) note that the system incorporated two major objectives: 'EQA system is in the form of a framework, with the majority of the activities undertaken being at the discretion of the academics who teach the courses. The system has been designed to achieve a balance between the autonomy of the academic as a professional and control by the organisation which carries formal responsibility for the conduct of activities within it.'

All those involved in the design and development of the University's system of Educational Quality Assurance go to pains to point out how this differs from industrial concepts of Total Quality Management (TQM). They reject ideas like those expressed in the US by Izadi, Kashef and Stadt (1996 :7) who suggest that 'TQM concepts may be used to improve qualities of an education system'. Bowden (1997) notes that as TQM notions of product, manufacturer, supplier and customer do not easily relate into the university context these concepts have little to offer higher education.

\subsection{Programme Quality Assurance (PQA)}

According to the University Web-site (RMIT 2002), the PQA system was designed to assist in managing, improving and assuring quality in the University's coursework programmes, and is based on a set of criteria that address issues of design, implementation and quality. It is intended to provide a framework for renewal of academic programmes and to help academics 'ensure that programmes are current, effective and well-managed.

An important aspect of the PQA system is the programme improvement process and this is based on the concept of continuous improvement cycles (Williams 2002) that are 'planned sequences of systematic and documented 
of the programme overall' (RMIT 2002). These activities include reflection, decision making, implementation, monitoring and feedback, and evaluation. The continuous improvement cycle is pictured in Figure 1 below.

The role played by the Programme Leader, who co-ordinates the Programme Team comprising the academic staff who teach and are responsible for each programme, is an important one in the PQA system. The Programme Leader facilitates Programme Team participation in PQA planning, review and renewal. It is the Programme Leader who is responsible for collecting input from Programme Team members relating to student feedback, and ensuring that all programme documentation is collected as part of the Programme Log. The idea of maintaining the Programme Log is to ensure that all programme documentation is kept in a form that assists the Programme Team to work effectively and to provide evidence of programme success. The Programme Log is kept up to date by entering this data into the Programme Quality Management system (PQM). The PQM system provides central access to all relevant programme information so that it is readily available to stakeholders in the University. It is a reference system used for filing either the actual programme documentation or details of the location of this documentation. It is intended to be used as a resource for academic and administrative staff, to provide background information for course re-writes, as a frame for ongoing programme review and to assist in the preparation of programme assessments and accreditation (Wahr, RMIT 2002).

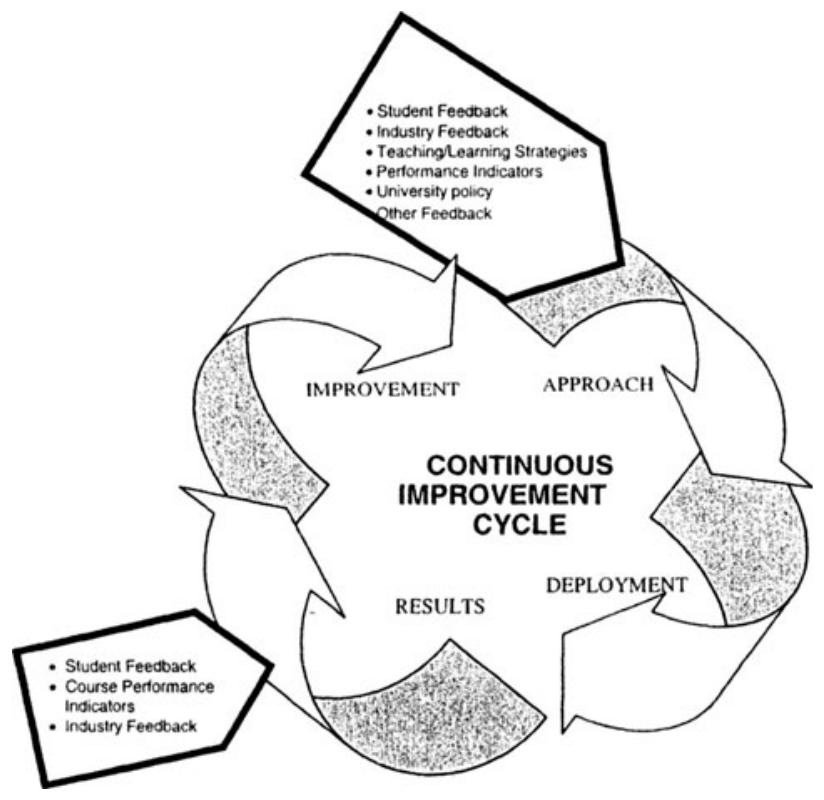

Figure 1: Continuous Improvement Cycle 


\section{RESEARCH RESULTS AND ANALYSIS}

In investigating the implementation and operation of the PQA system at the University the authors conducted semi-structured case study interviews with a number of Course Co-ordinators and other academics, PQA reviewers, and personnel involved in the planning and implementation of the PQA system. These interviews were tape recorded, and when later typed up, the interviewees were given a chance to make any for final correction. The questions asked were concerned with how the PQA system affected their work, what they though of the system, what they thought it might achieve in improving educational quality, and any implementation or other issues with the system that concerned them. We also sought out published papers on the topics of EQA and PQA and collected appropriate system documentation (Tatnall and Davey 1997) to complete the case study.

\subsection{Advantages and Disadvantages of the PQA System}

A Programme Leader thought the PQA system had both advantages and disadvantages. A significant disadvantage was producing all the paperwork which was time consuming. 'Sometimes I wish the system wasn't there because I just want to get on with my teaching and looking after the course without thinking about that; I just want to get on with it.' An advantage was having the documentation available. For instance, if someone else had to take over the course they could go and look in the log and see what had happened. It would then be fairly easy to pick it up.

Another Programme Leader pointed out what he considered to be a flaw in the system: the need to document everything. He instanced a situation where he ran into another academic in the corridor and asked 'what did you think of that last assignment?' If his colleague said 'oh it's no good, next time I think we should give it an extra week', under PQA he would be obliged to write a quality note to that effect, document this as a meeting and reflection, and indicate the change he intended making as a result. He noted that while this may have value, the paperwork overhead is 'absolutely stupendous'. When asked about how all this affected new developments in his programme he indicated that the time he needed to spend working on entering programme documentation into the system meant that he had little time to do any new curriculum development. 'So it may be that quality goes down because of quality assurance, but certainly the paperwork to prove you have quality greatly increases.' A comment from another Programme Leader is quite telling: 'One of the things I find most intrusive about it is how it actually takes away from actually delivering quality, and actually dealing 
with students, and doing scholarship and research that we all do all along the way.'

Finally, a comment from an experienced academic who has also acted as a Course Reviewer: 'I think it makes improvements steadily upwards. We had random change in the past - people made changes because they thought it was a good idea, everybody who took over a subject would re-invent the wheel. When you took over a subject documentation wasn't there for why things had happened in the past, so instead of making a change with due regard to the reasons for things being there, you made change in a vacuum. There was a lot of vacillation, so it's an improvement in that respect.'

\subsection{Problems with distance education in a global setting}

Like a number of other universities around the world (Buckingham and Channon 2002) the University has special problems with quality due to its global reach. Several interview subjects pointed out the quality problems arising from co-ordinating large, dispersed programmes with a supposedly common set of educational experiences. Typical of the viewpoint expressed by many academic staff was an interview with the co-ordinator of a large subject. 'The problem is we have a subject that runs in five countries as well as Australia. This subject leads on to others so it must produce a consistent result. People make changes for really good reasons: to improve cultural relevance, to allow for a different set of local conditions and such. It takes an enormous effort to try to keep everything together. We have normal staff turnover rates and advances from one person often get lost when the new person takes over.' Respondents also expressed dissatisfaction with previous systems of quality assurance based on measurement of performance indicators. Often the data used for these measurements came exclusively from student surveys. 'They just look at student survey responses. Once we had a real black mark because students in one country had experienced problems with poor reliability of computing equipment. If this survey data had been used to improve computers it would have been fine, but it just showed up as 'labs were not effective'.'

\subsection{Distance education staff response to the PQA}

Interviewees involved with the provision of subjects through distance modes were generally positive in two dimensions about the new system. These were the communications aspects of the requirement to document and store centrally, and the concept of allowing teams to choose their own quality improvement projects. A typical interview response came from a Team Leader of six years standing: 'the idea of an easy way of storing 
information on why changes needed to be made, what we did and if it worked was very attractive to me. If a new person came in to take over a country programme I could just show them the log and they could get up to speed really quickly. I think the other people (with local responsibility only) saw it all as a waste of time, but my job involves so much co-ordination effort that it was a godsend to me.'

\subsection{The Unique Nature of Australian Distance Education}

The description of distance offerings at the University has implications for quality. Most of the distance education consists of courses delivered traditionally in some places and by distance in several overseas locations. Prior to the introduction of the PQA, documentation for programmes resided in the offices of individual teachers around the University. The existence of a repository of descriptions and a system of centrally recording cycles of improvement made it possible for the large teams involved with global delivery to become co-ordinated.

The philosophy of documenting progress rather than measuring current parameters of output seems well suited to the task of delivery by large teams to very large groups of widely distributed students.

\section{CONCLUSION}

A number of academic staff still see the University's PQA system as a Machiavellian attempt to regulate and stifle professional freedom in course design and teaching. Given the size of the institution, the diversity of its staff, and the implementation mistakes described above, this view is understandable. Current use of the system does not, however, support this view. Another criticism of the system is the amount of time it takes to document the activities required. While sympathising with the Course Team Leaders who need to put in this time, we don't see how anyone could regard the existence of course documentation as a bad thing. If this needs the expenditure of some time then so be it.

The operation of the PQA system means that everything relating to a course, whether it occurs in a classroom or in distance education mode, is now documented. This includes course outlines, subject descriptions, assignments, resources and examination papers. Any academic who has had to take over an existing course after the departure of its previous Course Leader will be aware of the difficulties experienced in trying to collect 
details of what was done previously, but with the new PQA system that problem should now be a thing of the past.

Academics make improvements in the classroom, but previously they often have not taken the time, to document them. They thus don't get the credit, or the resources needed for improvement. Hopefully, when use of the PQA system has developed to the extent that it becomes second nature and a normal part of the academic routine, this documentation will automatically be produced without the need to think further about it.

We see the existence of a formal process to collect course data as an important success of the PQA system. On the other hand, the greatest problem with the system's implementation was the failure of those involved to appreciate, and allow for, how frightened some of the academic staff would be of the career consequences to them of the collection of this data.

On balance, we are of the view that the University's PQA system, despite some initial difficulties and a number of annoyances, offers an important path towards improving the quality of all the institution's educational programme, including those offered by distance education.

\section{REFERENCES}

Bowden, J. (1997). 'Continual Quality Improvement in Learning and Teaching through a Centralised Approach to Educational Quality Assurance. Managing the Quality of University Learning and Teaching.' J. A. Bowden and J. Sacks. http://www.deetya.gov.au/ divisions/hed/operations/Bowden/chapter8.htm\#headl, June 1997, Higher Education Division, Department of Employment, Education, Training and Youth Affairs.

Bowden, J. and P. Boyle (1995). 'Understanding RMIT's Approach to Educational Quality Assurance'. Melbourne, RMIT.

Buckingham, D. and N. Channon (2002). 'Distance Education, the Results of a Survey in Hong Kong'. http://www.qaa.uk/public/hq/hq10/hq10 distance.htm, The Quality Assurance Agency for Higher Education.

Gilroy, P., P. Long, et al. (2001). 'Evaluation and the Invisible Student: Theories, Practice and Problems in Evaluating Distance Education Provision.' Quality Assurance in Education 9(1): 14-22.

Izadi, M., A. E. Kashef, et al. (1996). 'Quality in Higher Education: Lessons Learned from the Baldrige Award, Deming Prize, and the ISO 9000 Registration.' Journal of Industrial Teacher Education 33(2): 60-76.

Marginson, S. (2002). 'The Phenomenal Rise of International Degrees Down Under.' Change 34(3): 34-43.

RMIT (2002). 'Enhancing Quality" http://www.rmit.edu.au/, RMIT.

Tatnall, A. and B. Davey (1997). 'A View of EQA in Business Computing at RMIT', Victoria University, Department of Business Computing.

Vidovich, L., M. Fourie, et al. (2000). 'Quality Teaching and Learning in Australian and South African Universities: Comparing Policies and Practices.' Compare 30(2): 193-209.

Williams, P. (2002). 'Continuous Improvement'. http://www.qaa.uk/public/hq/hq10/hq10 contents.htm, The Quality Assurance Agency for Higher Education. 